\title{
Genomic and geochemical identification of the long-chain alkenone producers in Lake Takahoko estuarine in Japan: Implications for temperature reconstructions
}

HIROTO KAJITA $^{1 *}$, HIDETO NAKAMURA ${ }^{2}$, NAOHIKO OHKOUCHI $^{3}$, NAOMI HARADA ${ }^{3}$, MIYAKO SATO ${ }^{3}$, SHUN TOKIOKA $^{4}$, HODAKA KAWAHATA ${ }^{1}$

${ }^{1}$ The University of Tokyo, Kashiwa 277-0882, Japan

(*correspondence: kajita@aori.u-tokyo.ac.jp)

${ }^{2}$ Osaka City University, Osaka 558-8585, Japan

${ }^{3}$ Japan Agency for Marine Earth Science and Technology,

Yokosuka 237-0061, Japan

${ }^{4}$ Fishery Research and Education Agency, Hachinohe 0310841, Japan

Identification of the lacustrine haptophytes that produce long-chain alkenones (LCAs) is necessary to establish lake water temperature reconstructions using alkenone unsaturation ratios $\left(\mathrm{U}^{\mathrm{K}}{ }_{37}\right)$. The presence of multiple alkenone producers have been considered to complicate the use of $\mathrm{U}^{\mathrm{K}} 37$ temperature proxy because each species can possess different temperature sensitivity.

We discovered LCAs in the brackish Lake Takahoko, in northern Japan. Using $18 \mathrm{~S}$ ribosomal DNA analysis, we identify two distinct genetic groups termed as Tak-A and Tak-B within Group II haptophyte phylotype. Tak-A was closely related to Hap-A[1], which was obtained from Lake George, USA; and Tak-B was identified as Isochrysis galbana. Because Hap-A and Isochrysis spp. may have similar $\mathrm{U}^{\mathrm{K}}$ 37-temperature calibrations[1, 2], Tak-A and Tak-B were also expected to share the similar calibrations. Therefore, the changes in their relative contribution in alkenone production should not significantly disturb the paleotemperature reconstructions. The alkenone temperature recorded in the surface sediment corresponded to the lake temperature in early to late summer. This is likely related to the haptophyte bloom season in Lake Takahoko.

Although it is necessary to carefully consider the changes in haptophyte species and bloom timing in the past, our study in Lake Takahoko suggested that brackish lake with multiple Group II haptophytes can be suitable for pateotemperature reconstruction[3].

[1] Theroux et al. (2019) Limnology and Oceanography 00, 1-13. [2] Araie et al. (2018) Organic Geochemistry 121, 89-103.[3] Kajita et al. (2020) Organic Geocemistry 103980. 